\title{
Effect of Chemical Composition on the Nanoscale Ordering Transformations of Physical Mixtures of Pd and Cu Nanoparticles
}

\author{
Vineetha Mukundan, ${ }^{1}$ Shiyao Shan, ${ }^{2}$ Chuan-Jian Zhong, ${ }^{2}$ and Oana Malis $\mathbb{D}^{1}$ \\ ${ }^{1}$ Department of Physics, Purdue University, West Lafayette, IN, USA \\ ${ }^{2}$ Department of Chemistry, State University of New York at Binghamton, Binghamton, NY, USA \\ Correspondence should be addressed to Oana Malis; omalis@purdue.edu
}

Received 27 April 2018; Revised 2 July 2018; Accepted 23 July 2018; Published 16 September 2018

Academic Editor: Yong Ding

Copyright (C) 2018 Vineetha Mukundan et al. This is an open access article distributed under the Creative Commons Attribution License, which permits unrestricted use, distribution, and reproduction in any medium, provided the original work is properly cited.

\begin{abstract}
The nanoscale composition and structure of alloy catalysts affect their performance in heterogeneous catalysis. In particular, previous reports indicated that $\mathrm{PdCu}$ nanoparticles are more efficient as catalysts in fuel cell reactions than monometallic Pd catalysts. To understand the structural transformations of $\mathrm{PdCu}$ nanoalloys, real-time in situ synchrotron $\mathrm{X}$-ray diffraction was used to examine the temperature-induced evolution of physical mixtures of $\mathrm{Pd}$ and $\mathrm{Cu}$ nanoparticles. Ex situ transmission electron microscopy measurements provide additional information about the size, phase, composition, and ordering of the nanoparticle mixtures. The results for $\mathrm{PdCu}$ mixtures of composition $1: 1$ and 3:1 supported on $\mathrm{SiO}_{2}$ are presented in detail here. The annealing procedure involved two stages: (a) isothermal annealing at $450^{\circ} \mathrm{C}$ and (b) ramped annealing from $450^{\circ} \mathrm{C}$ to $750^{\circ} \mathrm{C}$, both in forming gas atmospheres. We found the ordered $\mathrm{B} 2$ phase to be formed at $450^{\circ} \mathrm{C}$ in all compositions studied. Ramped annealing of $\mathrm{PdCu} 1: 1$ mixtures from $450^{\circ} \mathrm{C}$ to $750^{\circ} \mathrm{C}$ leads to the transformation of the $\mathrm{B} 2$ phase into two different alloys, one rich in $\mathrm{Cu}$ and the other rich in $\mathrm{Pd}$. This structural evolution bears the signature of spinodal decomposition and is different from that of PdCu bulk alloys. In PdCu 3:1 mixtures, the $\mathrm{B} 2$ phase dominates after isothermal annealing at $450^{\circ} \mathrm{C}$, but a significant disordered alloy fcc phase is also formed. During annealing at $750^{\circ} \mathrm{C}$, the disordered fcc phase grows at the expense of the B2 phase. These findings are important for the understanding of thermal activation of PdCu nanocatalysts for fuel cells.
\end{abstract}

\section{Introduction}

Nanostructured materials are ubiquitous and have many practical applications. Among them, noble metal nanoparticles are important as functional catalysts in fuel cells. In recent years, the strong growing interest in the development of fuel cells has triggered research on bimetallic nanoparticles as multifunctional catalysts. Nanocatalysts have the advantage that their properties can be engineered by tuning size and composition, alloying, and using phase transformations such as mixing, segregation, and ordering for surface structure. Many nanoalloy catalysts were found to be more efficient at catalyzing fuel cell reactions than the traditional bulk noble metals Pt and Au. However, commercialization of fuel cells is extremely sensitive to the high costs of the catalysts using Pt, Au, or their multimetallic combinations. For this reason, $\mathrm{Pd}$ nanoparticles have generated a lot of interest recently [1-5].

Pd has the potential to enable lower-cost catalysts for direct ethanol fuel cells (DEFCs) [1], carbon monoxide oxidation [2], oxidation reduction reaction [3], and catalytic denitrification reaction [4]. Shan et al. have found that $\mathrm{PdCu}$ nanoalloy catalysts are more stable in $\mathrm{CO}$ oxidation than $\mathrm{Pt}$ and Pt-based nanoalloys [2]. Pt and Pt-based nanoalloys are poisoned during these reactions and cannot be reused. $\mathrm{PdCu}$ was found to have higher mass activity than Pd for ethanol oxidation reaction in alkaline electrolyte [1]. DEFCs are more convenient than direct methanol fuel cells because ethanol is less toxic and can be obtained from biomass conversion of common agricultural products such as sugar cane and corn. The major challenge of DEFC is finding an efficient catalyst. Thermal annealing and postsynthesis treatment are 
required for the activation and stability of these catalysts. $\mathrm{PdCu}$ bimetallic nanoparticles not only are used as catalysts in fuel cells but also have important applications in the coal gasification process, selective hydrogenation of dienes, and hydrogen storage reactions.

Chemical composition drastically influences electrochemical activity because it determines the availability of active sites for heterogeneous catalysis. Changing the volume composition of an alloy affects the chemical distribution of surface sites such as edges and vertices. Since catalysis is governed by surface sites, the activity will consequently change with the concentration of metals in these active sites [6]. Shan et al. have shown that $\mathrm{Pd}_{50} \mathrm{Cu}_{50}$ nanoparticles have maximum activity of all compositions when thermochemically treated in the range of $200^{\circ} \mathrm{C}$ to $600^{\circ} \mathrm{C}$ in hydrogen and oxygen atmospheres [2]. Wang et al. [5] measured the electrocatalytic activity for different compositions of $\mathrm{PdCu}$ prepared by coimpregnation followed by reduction in hydrogen at $300^{\circ} \mathrm{C}$, $600^{\circ} \mathrm{C}$, and $800^{\circ} \mathrm{C}$. Both composition ratios $1: 1$ and $3: 1$ were found to have 4-5 times higher activity than monometallic $\mathrm{Pd}$. The highest activity was found for $\mathrm{PdCu} 1: 1$ at $600^{\circ} \mathrm{C}$ and $800^{\circ} \mathrm{C}$, and lower activity for $\mathrm{PdCu} 3: 1$. However, they reported the formation of a homogeneous $\mathrm{PdCu}$ alloy phase for the composition ratio $1: 1$ when heated at $600^{\circ} \mathrm{C}$. The degree of alloying and composition uniformity were also found to play a major role in the oxidation reduction reaction (ORR) [1-3].

Given these experimental electrochemical results, it becomes critical to understand the PdCu nanoparticle structural evolution during typical thermal and chemical processing conditions. Controlling the structure through phase transformations and chemical ordering is naturally the starting point for building specifically tailored functional nanomaterials. Numerous theoretical and experimental studies have been dedicated to understanding the correlation between structural changes and activity of Pt-based nanocatalysts [6], but not so much research has been done on Pd-based nanoalloys. This paper fills this knowledge gap by studying the phase transformations in $\mathrm{Pd}$ and $\mathrm{Cu}$ nanoparticle mixtures of different compositions. Unlike other reports in the literature that started with already alloyed nanoparticles [2-4], our path to multimetallic nanoparticles begins with pure $\mathrm{Pd}$ and $\mathrm{Cu}$ nanoparticles that are mixed in solution, dispersed on silica substrates, and then thermally treated at different temperatures in forming gas. In our previous work, we explored the behavior of $\mathrm{PdCu} 1: 2$ mixtures on different substrates in the temperature range from $25^{\circ} \mathrm{C}$ to $700^{\circ} \mathrm{C}$ [7]. We identified phase transformations from B2 (CsCl-type structure) to disordered fcc structure in the samples on $\mathrm{SiO}_{2} / \mathrm{Si}$ and carbon substrates during annealing in helium and forming gas. We also reported the formation of disordered alloys without the formation of the B2 phase in the case of $\mathrm{PdCu}$ nanoparticle mixtures dispersed on alumina. To complete our understanding of the nanoscale transformations in $\mathrm{PdCu}$ nanoparticle mixtures, this paper focuses on PdCu 1:1 and 3:1 mixtures. Synchrotron-based X-ray diffraction (XRD) and transmission electron microscopy were used to study the structure, size, alloying state, and elemental distribution of these nanoparticles. We specifically monitor the effect of initial compositions on the final chemical ordering of alloyed nanoparticles by a combination of $\mathrm{XRD}$ and electron microscopy measurements.

\section{Experimental Section}

2.1. Synthesis. Pure $\mathrm{Pd}$ and $\mathrm{Cu}$ nanoparticles were synthesized using metal precursors, reducing agents and capping agents as discussed in detail in our previous work $[1,7]$ and other works $[8,9]$. The separately synthesized $\mathrm{Pd}$ and $\mathrm{Cu}$ nanoparticles were added by volume to make up physical mixtures of different compositions. This work explores $\mathrm{PdCu}$ $1: 1$ and $3: 1$ mixtures. The nanoparticle mixtures were initially suspended in toluene. The mixtures were then dispersed on Si substrates covered with a $0.5 \mu \mathrm{m}$ thick thermal $\mathrm{SiO}_{2}$ layer. After air drying in a high-efficiency particulate air (HEPA) hood, the samples were preannealed at $200^{\circ} \mathrm{C}$ in air on a hot plate for ten minutes. This was done to remove the capping agents by oxidation in air [10] to prevent them from forming different $\mathrm{Pd}$ and $\mathrm{Cu}$ compounds (e.g., $\mathrm{Cu}_{2} \mathrm{~S}$ and $\mathrm{PdO}_{2}$ ) [4]. After cooling the samples to room temperature in a HEPA hood, they were loaded into the XRD vacuum chamber. Using a combination of a rotary pump and a turbomolecular pump, the pressure in the chamber was brought down to $10^{-6}$ torr. Then, the chamber is purged with $\mathrm{He}$ gas. Under these conditions of pressure and preannealing, we expect the capping agents to be completely removed from the samples [10]. Before the start of the experiments, the atmosphere in the chamber was changed to forming gas (nitrogen gas with $5.17 \%$ hydrogen).

2.2. Instrumentation and Measurements. Structural parameters such as size, composition, and chemical ordering were probed by in situ time-resolved synchrotron-based X-ray diffraction and by ex situ transmission electron microscopy (TEM).

2.2.1. In Situ Time-Resolved Synchrotron-Based X-Ray Diffraction. These experiments were performed using the beamline X20C at the National Synchrotron Light Source (NSLS), Brookhaven National Laboratory (BNL). The X-ray energy used here is $6.9 \mathrm{keV}$ (1.79 $\AA$ wavelength). This beamline has a custom vacuum chamber, linear position-sensitive detector, and rapid thermal annealing stage with the capability of flowing different gases such as high-purity $\mathrm{He}$ and forming gas $\left(5.17 \% \mathrm{H}_{2}\right.$ in $\left.\mathrm{N}_{2}\right)$. The XRD pattern in the $2 \theta$ angular range from 40 to $60^{\circ}$ (corresponding to fcc (111) and (200) peaks) was recorded using a linear detector with two-second time resolution. The in situ experiments for this study were carried out in forming gas, and the annealing procedure consisted of two steps: (a) isothermal annealing at $450^{\circ} \mathrm{C}$ and (b) ramped annealing from $450^{\circ} \mathrm{C}$ to $750^{\circ} \mathrm{C}$ at a rate of $40^{\circ} \mathrm{C} / \mathrm{min}$. Each of these experiments lasted $630 \mathrm{sec}-$ onds. The analysis of the XRD data involved fitting the diffraction peaks with a series of Lorentzians to extract lattice parameter, crystallite size, and phase volume.

2.2.2. Transmission Electron Microscopy. Low-magnification and high-resolution TEM was performed on an FEI Titan TEM at Purdue University with an acceleration voltage of 


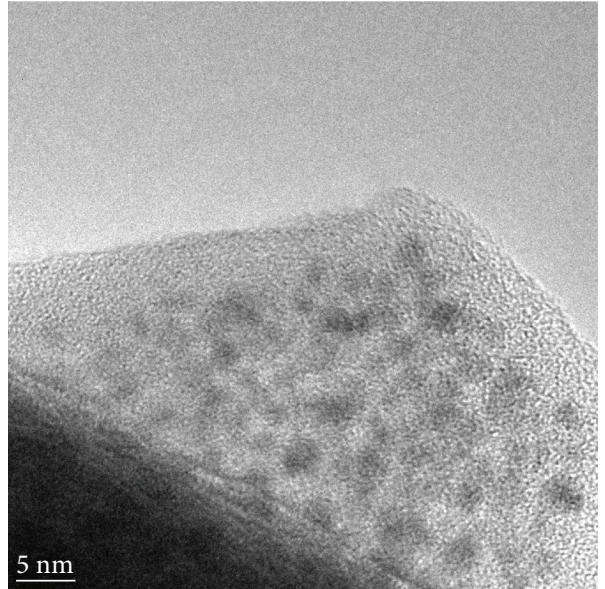

(a)

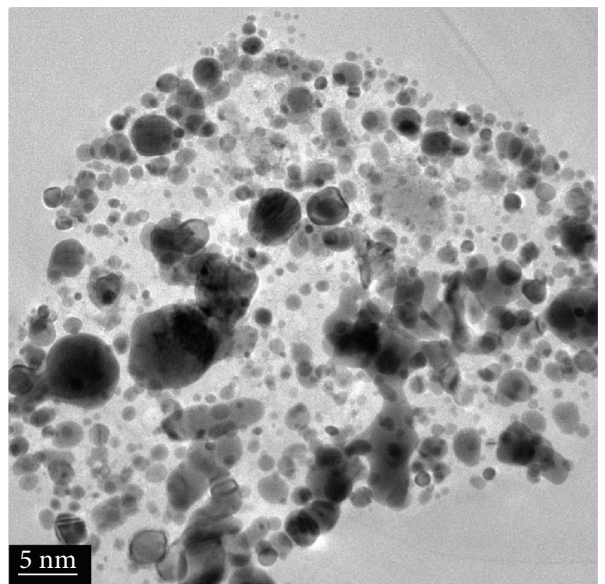

(c)

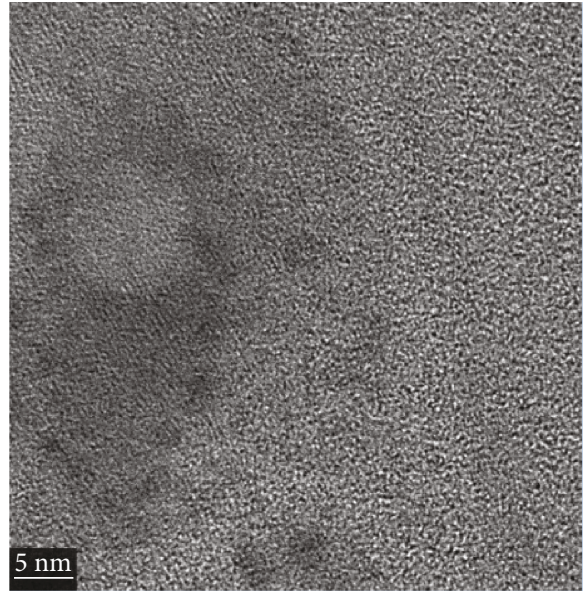

(b)

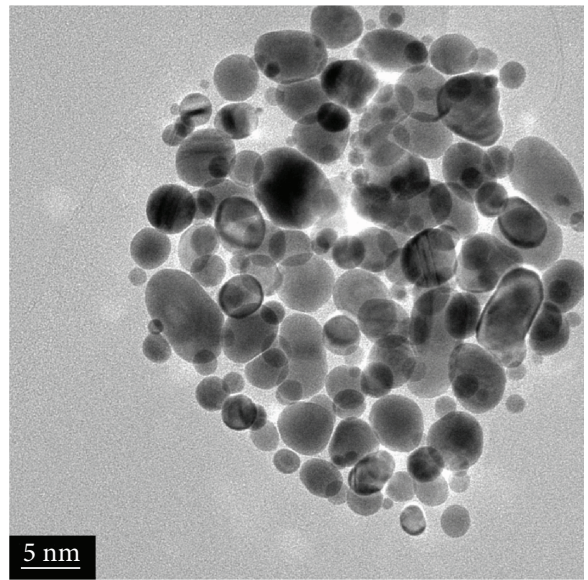

(d)

Figure 1: (a) TEM image of the as-synthesized Cu nanoparticles (scale bar is $5 \mathrm{~nm}$ ). (b) TEM image of as-synthesized Pd nanoparticles (scale bar is $5 \mathrm{~nm}$ ). (c) TEM image of PdCu 1:1 nanoparticle mixtures after annealing at $750^{\circ} \mathrm{C}$ in forming gas (scale bar is $50 \mathrm{~nm}$ ). (d) TEM image of $\mathrm{PdCu} 3: 1$ nanoparticle mixtures after annealing at $750^{\circ} \mathrm{C}$ in forming gas (scale bar is $50 \mathrm{~nm}$ ).

$300 \mathrm{keV}$ and with $0.24 \mathrm{~nm}$ point-to-point resolution. The nanoparticles annealed in the XRD studies were transferred from the $\mathrm{Si}$ wafer to thin carbon film-coated copper grids in hexane and plasma annealed to get rid of the hexane and carbonaceous materials in the sample. The image files were processed using the Digital Micrograph and ImageJ software for studying the lattice parameter and obtaining the size distribution of the particles. The fast Fourier transform images were obtained for the high-resolution images and were compared to patterns generated by SingleCrystal software to verify the lattice parameter and zone axis.

The sizes of the pure $\mathrm{Cu}$ nanoparticles and for the pure Pd nanoparticles are $3.5 \pm 1 \mathrm{~nm}$ (Figure 1(a)) and $2 \pm 1 \mathrm{~nm}$, respectively (Figure 1(b)). After annealing the $\mathrm{PdCu}$ nanoparticle mixtures, they have different size distributions. At the end of all thermal treatments, the nanoparticles in the $\mathrm{PdCu} 1: 1$ mixture have the size of $22.9 \pm 7.4 \mathrm{~nm}$ from counting 350 nanoparticles, while the nanoparticles from the $\mathrm{PdCu}$ $3: 1$ mixture have the size of $23.3 \pm 13.8 \mathrm{~nm}$ from counting 550 nanoparticles.

We also investigated the composition of the $\mathrm{PdCu}$ nanoparticle mixtures using high-angle annular dark-field scanning transmission electron microscopy (HAADFSTEM) and energy dispersive X-ray spectroscopy (EDX). STEM analysis is important to distinguish between the metallic nanoparticles and the organic capping agent, if present. EDX measurements are essential for elemental analysis. Energy dispersive X-ray analysis was performed with the EDX detector attached to the Titan TEM. The EDX detector used here was the X-Max Silicon Drift Detector manufactured by Oxford Instruments. The EDX spectral acquisition was done using the Aztec Energy software. For EDX experiments, the nanoparticle mixtures were dispersed on a thin C film on gold-coated grids. Since the specimens contain $\mathrm{Cu}$ nanoparticles, grids of a different metal are preferable to prevent the contribution of the grids to the $\mathrm{X}$-ray signal while evaluating the atomic compositions of the specimen.

\section{Results}

The bulk PdCu phase diagram shown in Figure 2 reveals that $\mathrm{PdCu}$ alloys can take several crystalline structures and undergo solid-phase structural transformations that depend on temperature and composition [11]. The compositions 


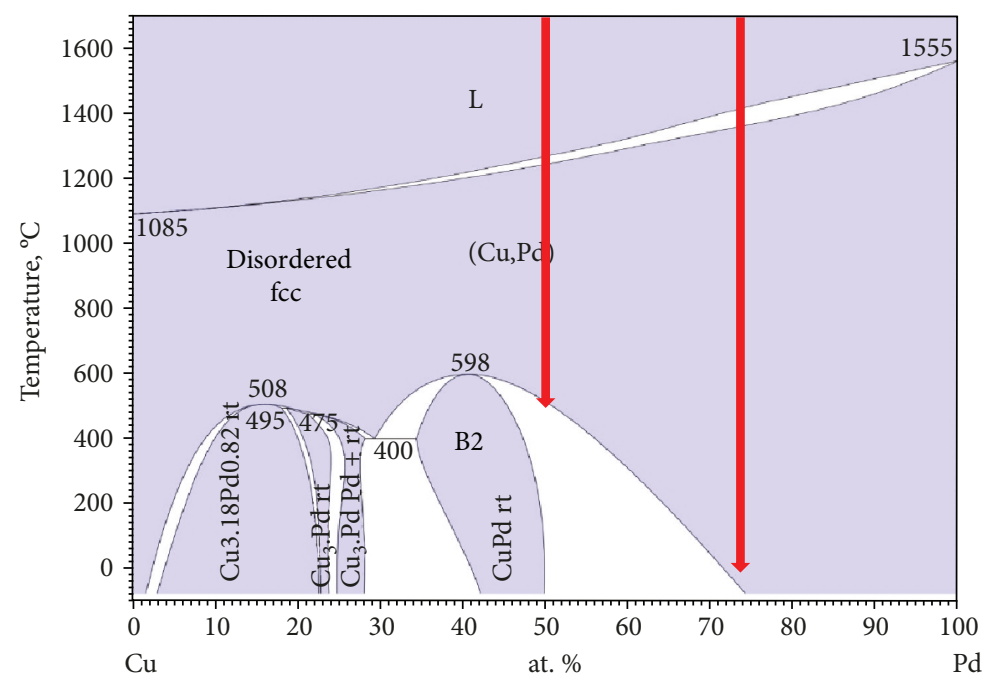

FIGURE 2: Phase diagram of bulk PdCu [11]. Reprinted with permission of ASM International. All rights reserved. http://www.asminternational.org. See also [7].

examined in this paper are marked by red arrows and correspond to (a) 50 at. \% Pd and (b) 75 at. \% Pd. For $40-50 \%$ Pd, we notice that the room temperature stable phase is an ordered CsCl-type phase named B2. The B2 phase transforms into a disordered fcc structure at high temperatures. Above 50 at. \% Pd composition, the two structures can also coexist. For 75 at. \% Pd, the likelihood of formation of the B2 phase in bulk alloys is relatively small. We found that during thermal treatment, $\mathrm{PdCu}$ nanoparticle mixtures behave differently compared to what was expected from bulk alloys of similar composition.

3.1. PdCu 1:1 Nanoparticle Mixtures. These PdCu nanoparticle samples were prepared by mixing Pd nanoparticles and $\mathrm{Cu}$ nanoparticles in the ratio $1: 1$ by volume. We monitored the structural evolution of the PdCu nanoparticle mixture in two thermal treatments. Figure 3 shows the color map of the $\mathrm{XRD}$ intensity evolution in the two thermal treatments.

For the isothermal annealing at $450^{\circ} \mathrm{C}$, the temperature is ramped from $25^{\circ} \mathrm{C}$ to $450^{\circ} \mathrm{C}$ at a rate of $1000^{\circ} \mathrm{C} / \mathrm{min}$ and stabilizes at $450^{\circ} \mathrm{C}$ in less than 20 seconds. Figure 3(a) shows that during this annealing step, a peak grows at a $2 \theta$ angle of $50.71 \pm 0.03^{\circ}$ that corresponds to the (110) of the B2 phase. This indicates that the two metals intermix forming $\mathrm{PdCu}$ nanoparticles with a predominantly B2 structure, similar to observations for other compositions [2, 3, 7, 12]. From the analysis of the XRD data, we estimate the lattice parameter of the B2 structure to be $2.96 \pm 0.001 \AA$ and the grain size to be $13.24 \pm 0.98 \mathrm{~nm}$. This lattice parameter corresponds to the (110) plane of the PdCu B2 structure (Pm3-m space group) as confirmed by the work of Yamauchi and Tsukuda [13]. Additional verification of this phase was obtained by HRTEM analysis as shown in our previous work [7]. We also note the formation of a small volume of a Pd-rich phase with estimated composition of $71 \%$ Pd (similar to Alloy-2 discussed below).

The second step in the annealing protocol is increasing the temperature from $450^{\circ} \mathrm{C}$ to $750^{\circ} \mathrm{C}$ at a ramp rate of $30^{\circ} \mathrm{C} / \mathrm{min}$ after 30 seconds at $450^{\circ} \mathrm{C}$. Here, a complex change involving phase transformation and phase segregation is witnessed. The PdCu B2 structure transforms into two different fcc alloy structures. The B2 structure having a lattice parameter of $2.96 \pm 0.01 \AA$ transforms into (a) an fcc alloy structure with a lattice parameter of $3.67 \pm 0.01 \AA$ indicated by the peaks at angles $49.9 \pm 0.2^{\circ}$ and $58.3 \pm 0.1^{\circ}$ corresponding to the fcc (111) and fcc (200) planes (denoted as Alloy-1 here on) and (b) a secondary fcc alloy structure with a lattice parameter of $3.81 \pm 0.01 \AA$ characterized by peaks at angles $48.1 \pm 0.1^{\circ}$ and $56.2 \pm 0.2^{\circ}$ corresponding to the fcc (111) and fcc (200) planes (denoted as Alloy-2 here on). Using the Debye-Scherrer relation, the grain sizes corresponding to the fcc (111) direction for Alloy-1 and Alloy-2 were found to be $20.5 \pm 6.9 \mathrm{~nm}$ and $13.6 \pm 1.4 \mathrm{~nm}$, respectively. We also observe the presence of the two different alloy phases in the $\theta-2 \theta$ XRD scan taken after the samples annealed at $750^{\circ} \mathrm{C}$ were quenched to room temperature as shown in Figure 3(c). A closer look at Alloy-1 (111) peak indicates that the B2 (110) phase may have survived in a small fraction. This may be due to the fact that the phase transformation is not complete over the temperature and time ranges examined.

From XRD data, using Vegard's law, we can calculate the lattice parameter to find the \% content of each of the metals in the alloy nanoparticles. From the smaller lattice parameter of Alloy-1, we find the $\mathrm{Cu}$ content in the nanoparticles to be $78 \%$, with a Pd composition of only $22 \%$. For Alloy-2, we find the $\mathrm{Cu}$ content to be $29 \%$, corresponding to a Pd content of $71 \%$. Therefore, we report the formation of two alloys, one rich in $\mathrm{Cu}$ and another rich in Pd. This structural evolution is unique and has not been observed previously either in $\mathrm{PdCu} 1: 2$ composition [7] or in $\mathrm{PdCu} 3: 1$ composition as will be discussed in the next section.

The structure of the $\mathrm{PdCu} 1: 1$ nanoparticle mixture annealed at $750^{\circ} \mathrm{C}$ was also confirmed by high-resolution TEM images. After annealing in forming gas at $750^{\circ} \mathrm{C}$, the analysis of the TEM images (shown in Figure 1(c)) estimated the average size to be $22.9 \pm 7.4 \mathrm{~nm}$ from counting 350 


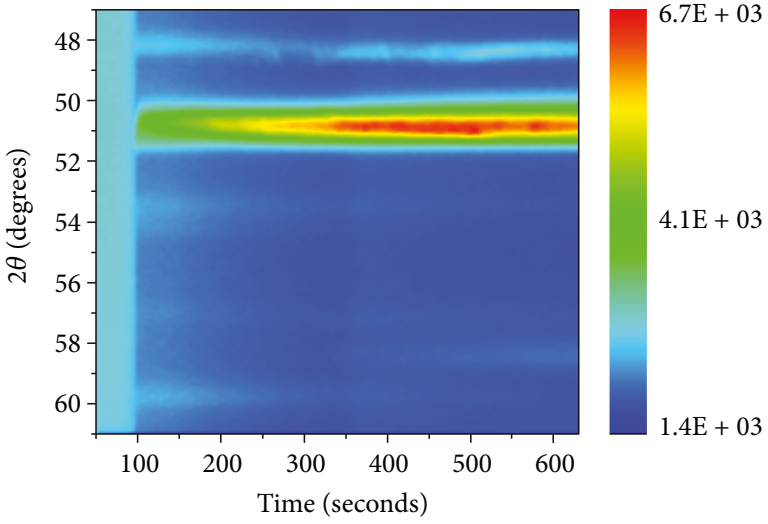

(a)

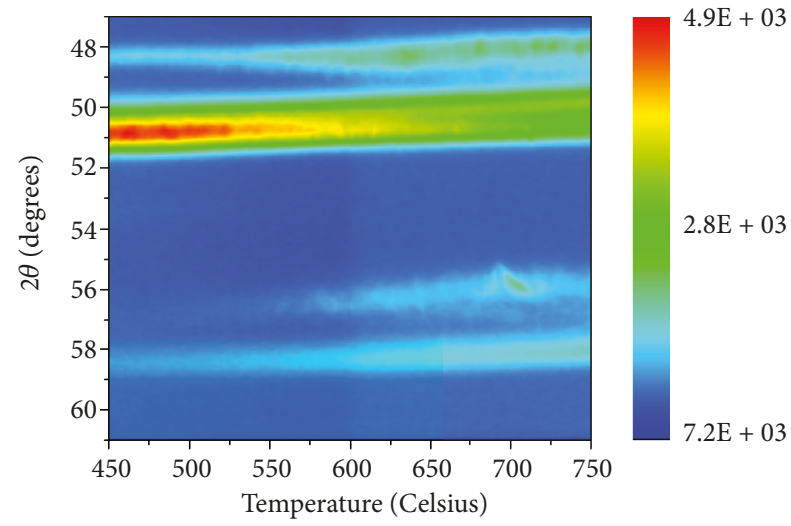

(b)

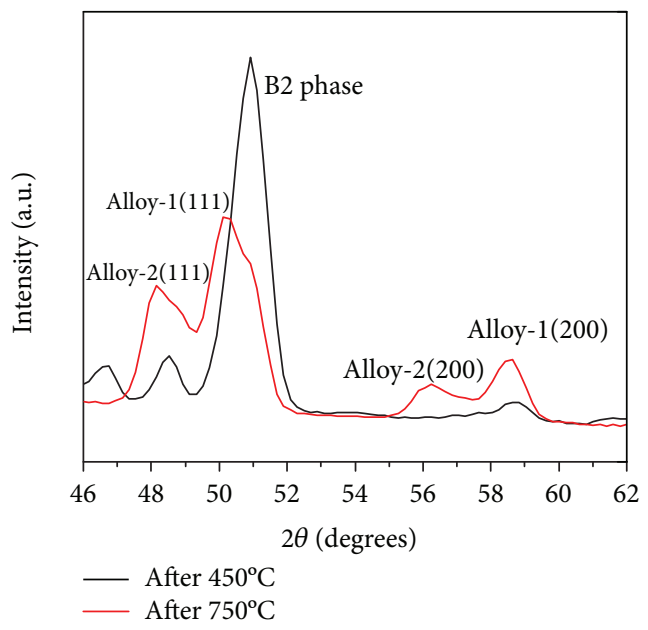

(c)

Figure 3: (a) Color map of the XRD intensity evolution for the $\mathrm{PdCu} 1: 1$ nanoparticle mixture on the $\mathrm{SiO}_{2} / \mathrm{Si}$ substrate isothermally annealed at $450^{\circ} \mathrm{C}$ in a forming gas atmosphere showing the formation of the ordered $\mathrm{B} 2$ phase (see also [7]). The heating process started at time 60 sec. (b) Color map of the XRD intensity evolution of the $\mathrm{PdCu}$ nanoparticle mixture on the $\mathrm{SiO}_{2} / \mathrm{Si}$ ramp annealed from $450^{\circ} \mathrm{C}$ to $750^{\circ} \mathrm{C}$ in a forming gas atmosphere showing the transformation of the B2 phase into two disordered fcc alloy phases. (c) $\theta-2 \theta$ XRD scans after annealing at $450^{\circ} \mathrm{C}$ and $750^{\circ} \mathrm{C}$.

nanoparticles. Figure 4(a) further corroborates the existence of two different alloy structures. The fast Fourier transform (FFT) of specific regions reveals the zone axis and lattice fringes along a particular plane. Figure 4(b) reveals the lattice fringe of $2.19 \AA$ of the (111) plane. Figure 4 (c) is the FFT of Figure 4(b) showing the [211] zone axis of Alloy-1 (Fm-3m space group) [14]. Similarly, Figure 4(e) shows the lattice fringe of $1.93 \AA$ of the (002) plane, while Figure $4(\mathrm{~d})$ is the FFT of Figure 4(e) showing the [110] zone axis of Alloy-2 (Fm-3m space group) [15]. These high-resolution images of the $\mathrm{PdCu}$ alloy nanoparticles confirm the crystalline nature of the two alloys. Conventional TEM images of different regions of the sample did not reveal any morphological differences corresponding to the two different alloys formed in these samples.

The composition and phase segregation observed in the XRD were further confirmed by the EDX and HAADFSTEM analyses on these samples. HAADF-STEM of such nanoparticles is shown in Figure 5(a), and it revealed a relatively uniform alloy distribution in each nanoparticle. Even though HAADF-STEM with atomic resolution should be sensitive enough to distinguish the two different alloy structures of the nanoparticles, the quality of our images did not allow us to do so. The bright regions in the HAADF-STEM images are attributed to more atomic columns in regions of nanoparticle overlap, not to different atomic compositions.

EDX maps of the nanoparticles also showed relatively uniform distribution of $\mathrm{Pd}$ and $\mathrm{Cu}$ in each alloy nanoparticle. However, EDX point scans revealed composition variation in different regions of the nanoparticle mixture probed. Figure 5(a) shows the HAADF-STEM image of an alloy nanoparticle aggregate formed from the annealing protocol followed in this study, and the corresponding table reveals the atomic percentages from the EDX spectra (Figures 5(b) and 5(c)) at different spots on Figure 5(a). This confirms the formation of two alloy structures in these $\mathrm{PdCu}$ nanoparticle mixtures with different atomic percentages of $\mathrm{Pd}$ and $\mathrm{Cu}$ as shown in the table in Figure 5. We speculate the formation of Pd-rich and $\mathrm{Cu}$-rich phases by spinodal decomposition. Given that both phases were segregated from the same B2 

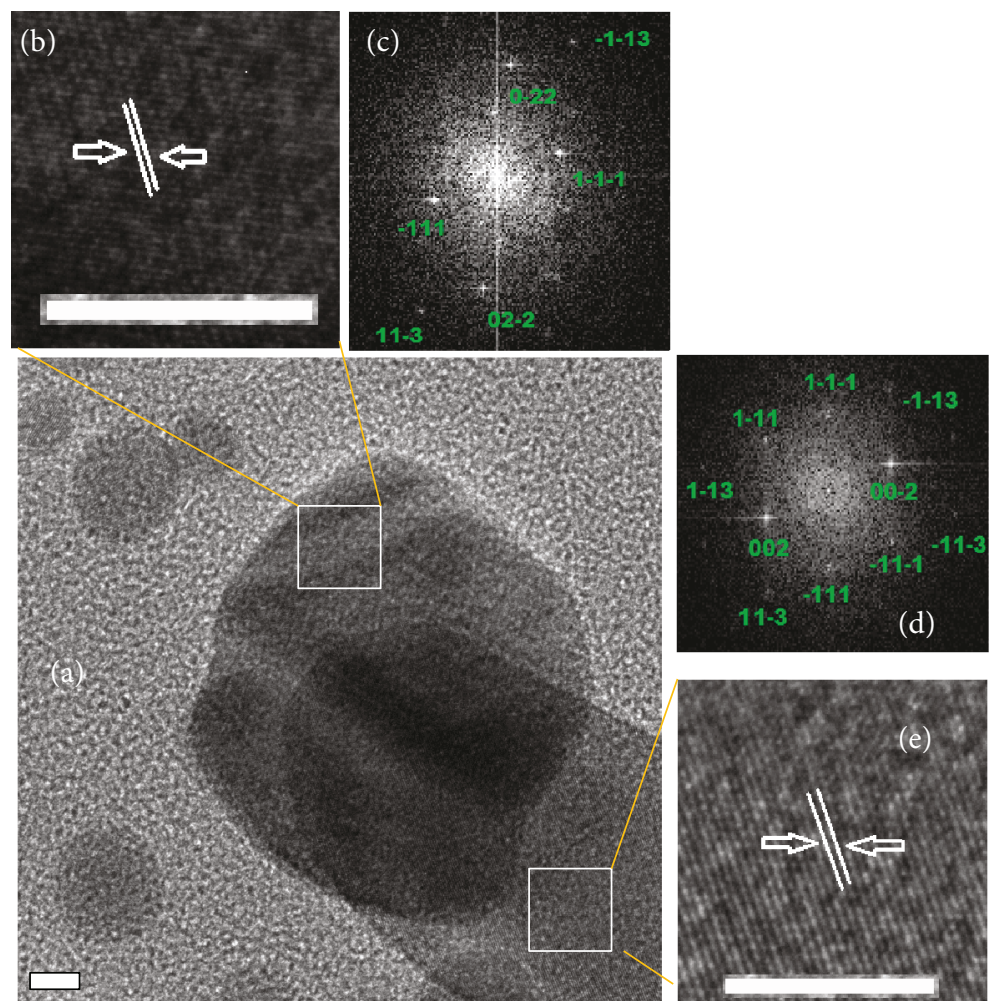

FIgURE 4: (a) TEM image of the $\mathrm{PdCu} 1: 1$ nanoparticle mixture after ramp annealing at $750^{\circ} \mathrm{C}$ on the $\mathrm{SiO}_{2} / \mathrm{Si}_{\text {s }}$ substrate in a forming gas atmosphere. (b) High-resolution image of the $\mathrm{PdCu}$ particle marked in (a) reveals uniform lattice fringes across the particle with an interplanar distance of $2.19 \AA$ that corresponds to the [111] plane of the Alloy-1 phase. (c) The FFT from a marked area in (b) is indexed as the [211] zone axis of the PdCu Alloy-1 phase. (e) High-resolution image of another PdCu particle marked in (a) reveals uniform lattice fringes across the particle with an interplanar distance of $1.93 \AA$ that corresponds to the [002] plane of the Alloy-2 phase. (d) The FFT from a marked area in (e) is indexed as the [110] zone axis of the PdCu Alloy-2 phase. Scale bars are $5 \mathrm{~nm}$ for images (a), (b), and (e).

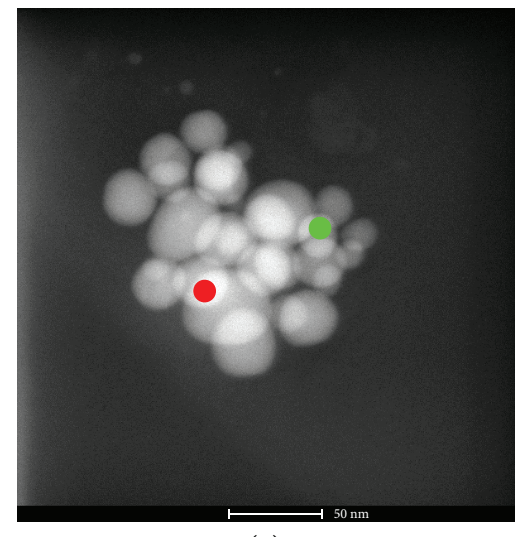

(a)

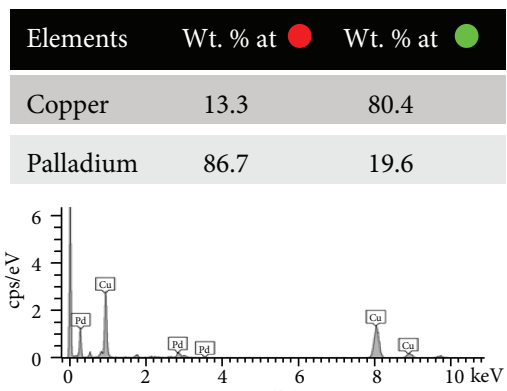

(b)

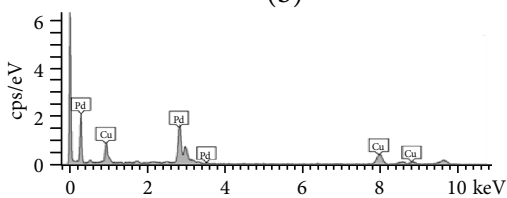

(c)

Figure 5: (a) HAADF-STEM image of the PdCu $1: 1$ nanoparticle mixture after ramp annealing at $750^{\circ} \mathrm{C}$ on the $\mathrm{SiO}{ }_{2} / \mathrm{Si}$ substrate in a forming gas atmosphere. Scale bar is $50 \mathrm{~nm}$. (b) EDX spectrum obtained for green point in (a). (c) EDX spectrum obtained for red point in (a). Table: Pd and $\mathrm{Cu}$ wt. \% compositions measured from the spectra in (b) and (c).

structure, the two alloy phases may coexist in each nanoparticle or may have separated into isolated nanoparticles.

We note that the formation of the fcc phase with a lattice parameter of $3.8 \AA$, corresponding to diffraction peaks at $49.9 \pm 0.2^{\circ}$ and $58.3 \pm 0.1^{\circ}$ in Figure 3(c), was observed for
PdCu 1:1 and 3:1 mixtures, but not for $1: 2$ composition [7]. It may be attributed to a PdCu alloy of high Pd content or to $\mathrm{PdCl}_{2}$. The possibility of $\mathrm{PdCl}_{2}$ formation was ruled out because EDX scans did not measure any chlorine signal in the nanoparticles. Since $\mathrm{PdCu}$ nanoalloys at 50:50 


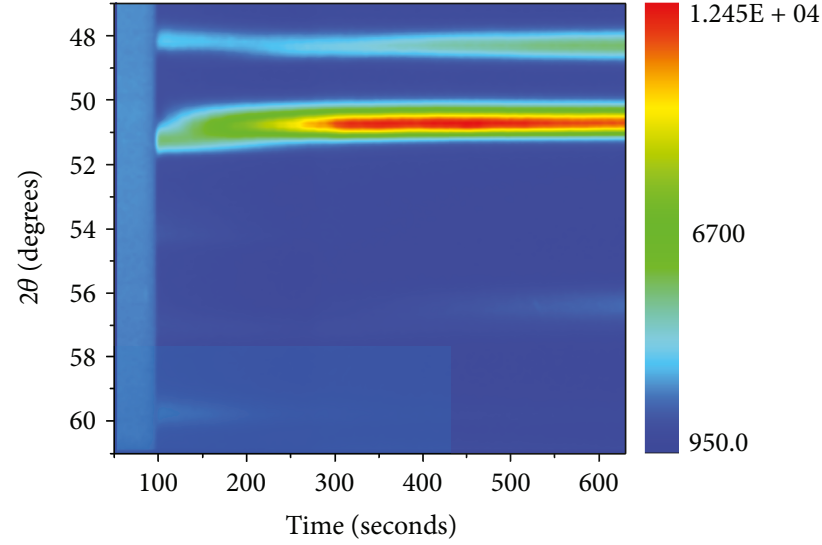

(a)

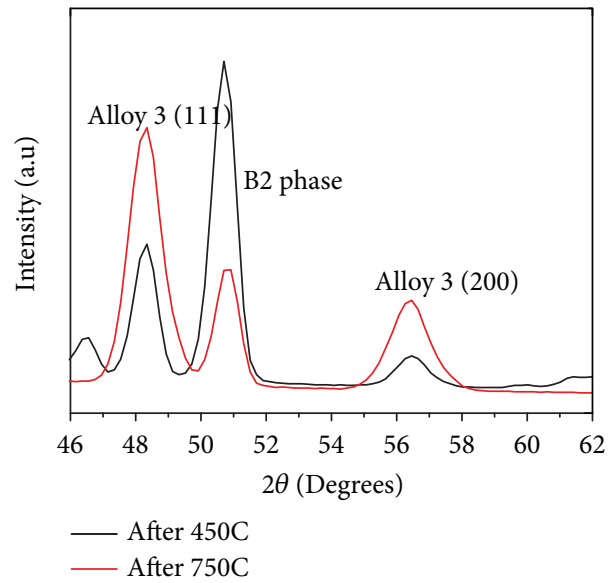

(c)

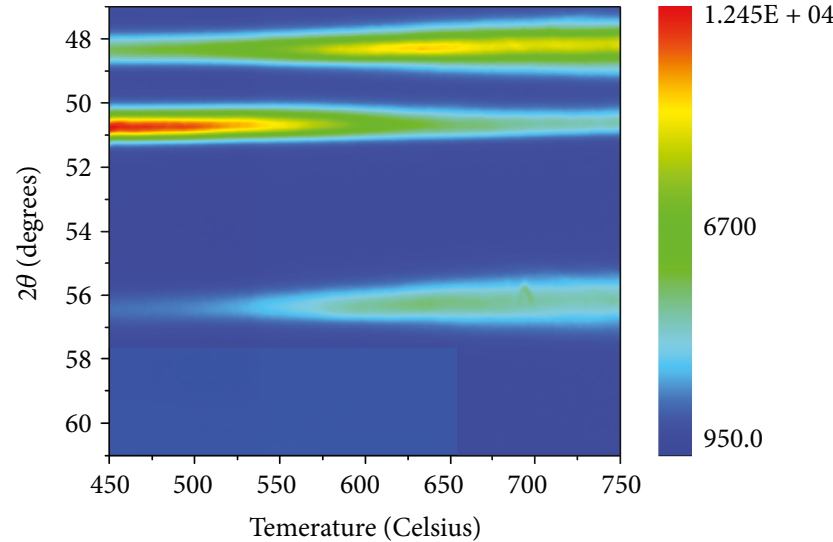

(b)

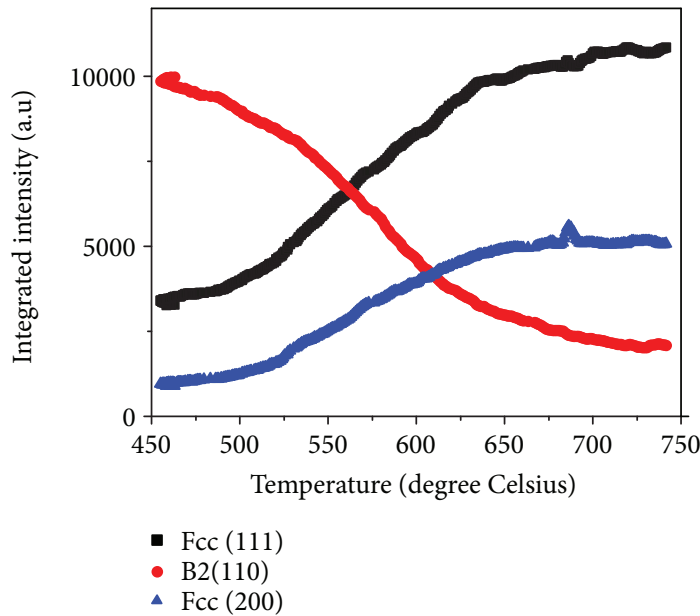

(d)

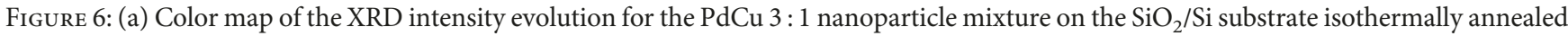
at $450^{\circ} \mathrm{C}$ in a forming gas atmosphere showing the formation of the ordered $\mathrm{B} 2$ phase and another alloyed phase (see also [7]). The heating process started at time $60 \mathrm{sec}$. (b) Color map of the XRD intensity evolution of the $\mathrm{PdCu}$ nanoparticle mixture on the $\mathrm{SiO} / \mathrm{Si}$ ramp annealed from $450^{\circ} \mathrm{C}$ to $750^{\circ} \mathrm{C}$ in a forming gas atmosphere showing the incomplete transformation of the B2 phase into the disordered fcc alloy phase. (c) $\theta-2 \theta$ XRD scans after annealing at $450^{\circ} \mathrm{C}$ and $750^{\circ} \mathrm{C}$. (d) Time evolution of the calculated XRD integrated intensities corresponding to the various peaks shown in (b) during ramp annealing from $450^{\circ}$ to $750^{\circ} \mathrm{C}$.

composition were found to have maximum catalytic activity [2], it is possible that the improved catalytical activity is related to the phase segregation described above in $\mathrm{PdCu}$ mixtures with a composition of $1: 1$.

3.2. PdCu 3: 1 Nanoparticle Mixtures. The Pd and Cu metallic nanoparticles in toluene synthesized separately were also mixed in the ratio $3: 1$ by volume. When annealed at $450^{\circ} \mathrm{C}$ isothermally, the $\mathrm{PdCu}$ 3:1 nanoparticle mixture showed the presence of two structures: a dominant B2 phase and an fcc alloy phase (Alloy-3) as shown in Figure 6(c). The B2 phase has a (110) peak at $50.7^{\circ}$, and the calculated lattice parameter is $2.96 \pm 0.005 \AA$. There are additional peaks at $48.16 \pm 0.05^{\circ}$ and $56.62 \pm 0.21^{\circ}$ which correspond to the fcc structure (111) and (200) planes, respectively, as seen in Figures 6(a) and 6(c). The growth of the ordered phase (B2) and the Alloy-3 phase is not simultaneous. The corresponding lattice parameter of the dominant (111) fcc structure is $3.80 \pm 0.004 \AA$, and the crystallite size is $20.9 \pm 1.3 \mathrm{~nm}$.
During annealing from $450^{\circ} \mathrm{C}$ to $750^{\circ} \mathrm{C}$, there were changes in structure as evidenced in Figure 6(b). Here, the B2 phase is observed to transform into the Alloy-3 phase. In Figure 6(c), this was confirmed by the $\theta-2 \theta$ scans done on the sample after quenching to room temperature from $450^{\circ} \mathrm{C}$ and $750^{\circ} \mathrm{C}$, respectively. The integrated intensity plot in Figure $6(\mathrm{~d})$ reveals that the $\mathrm{B} 2$ phase decreases steadily above $550^{\circ} \mathrm{C}$, whereas the fcc alloy grows with temperature. The average size of the B2 phase calculated from the $\theta-2 \theta$ scans is $17.5 \pm 2.2 \mathrm{~nm}$ after annealing at $450^{\circ} \mathrm{C}$. At the end of the $750^{\circ} \mathrm{C}$ treatment, the average size of the dominant fcc (111) phase is $21.1 \pm 1.8 \mathrm{~nm}$. The transformation of the ordered B2 phase into the disordered fcc phase is incomplete, as evidenced by the survival of a B2 (110) peak at the end of the high-temperature treatment.

The TEM analysis of the nanoparticles annealed in forming gas at $750^{\circ} \mathrm{C}$ (Figure $1(\mathrm{~d})$ ) estimated the average size to be $23.25 \pm 13.8 \AA$ from counting 550 nanoparticles. The highresolution TEM images (Figure $7(\mathrm{a})$ ) of the $\mathrm{PdCu} 3: 1$ nanoparticle mixtures substantiate the formation of the Alloy-3 


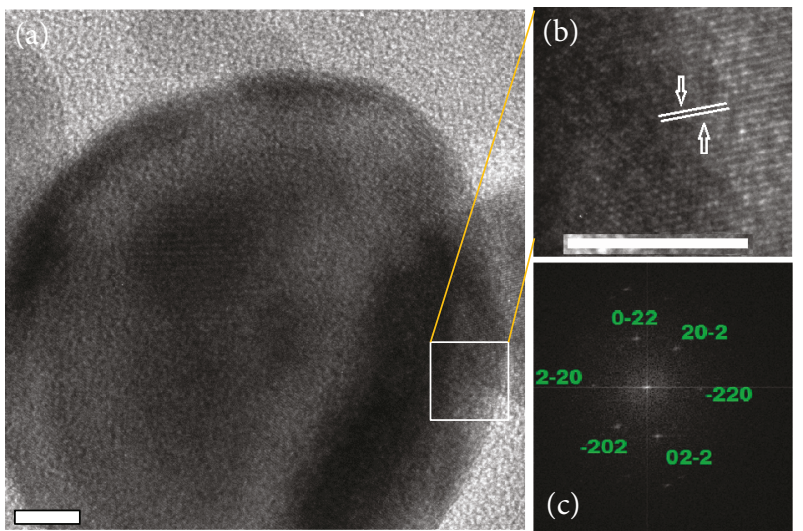

FIgure 7: (a) TEM image of the PdCu 3:1 nanoparticle mixture after ramp annealing at $750^{\circ} \mathrm{C}$ on the $\mathrm{SiO}_{2} / \mathrm{Si}$ substrate in a forming gas atmosphere. (b) High-resolution image of a $\mathrm{PdCu}$ particle marked in (a) reveals uniform lattice fringes across the particle with an interplanar distance of $2.14 \AA$ that corresponds to the [110] plane of the Alloy-3 phase. (c) The FFT from a marked area in (a) is indexed as the [111] zone axis of the PdCu Alloy-3 phase. Scale bars are $5 \mathrm{~nm}$ for images (a) and (b), respectively.

phase with Pd-rich content after annealing at $750^{\circ} \mathrm{C}$. Figure 7 (b) shows a blowup of the lattice fringes with a spacing of $2.16 \AA$ corresponding to the (111) lattice plane of Alloy-3 (Fm-3m space group) [11]. The FFT of the region corresponds to the [111] zone axis of Alloy-3 (Figure 7(c)).

Using Vegard's law with the XRD data, the Cu content of the dominant fcc phase obtained after annealing at $750^{\circ} \mathrm{C}$ was estimated to be $29 \%$. The Alloy- 3 composition was further verified with EDX analysis shown in Figure 8. EDX found the $\mathrm{Cu}$ composition to be $24 \%$, in agreement with the value calculated from XRD data.

\section{Discussion}

The stability ranges of various structures in alloy systems are important for the understanding of their functional properties. They are affected by temperature, size, chemical environment, substrates, etc. Shan et al. [2] have examined the electrocatalytic activity of $\mathrm{Pd}_{50} \mathrm{Cu}_{50}$ nanoparticles and found a phase segregation into two different alloy phases when annealed in a combination of oxygen and hydrogen on carbon substrates up to $400^{\circ} \mathrm{C}$ [2]. Using atomic pairdistribution function analysis of high-energy synchrotron $\mathrm{X}$-ray diffraction, they identified the coexistence of the chemically ordered B2 alloy phase and disordered fcc alloy phase. At the lower or higher composition ratio of $\mathrm{PdCu}$, a single fcc-type alloy phase was observed. Hydrogenation activity of PdCu nanoparticles, especially in the case of $1: 1$ composition, was explored on different substrates such as alumina, ceria, and titania [4]. PdCu with $1: 1$ composition on alumina was found to have the highest activity [2]. However, this electrochemical activity was found to degrade most rapidly for $\mathrm{Pd}_{50} \mathrm{Cu}_{50}$ nanoparticles during operation in a fuel cell [16]. This degradation was attributed to leaching of $\mathrm{Cu}$ atoms and the formation of different alloy phases [16].
In our study of nanoparticle mixtures, we found that the structure of $\mathrm{PdCu}$ nanoparticle mixtures evolves in a different manner compared to what was expected from the bulk phase diagram (Figure 2). The bulk phase diagram indicates the formation of the $\mathrm{B} 2$ phase at low temperatures in a relatively narrow composition range (35-50\% $\mathrm{Pd}$ ) and the transformation to disordered fcc alloys at higher temperature. In contrast, for the nanoparticle mixtures used in this study, we see a dramatically different behavior. The B2 phase was formed during annealing at $450^{\circ} \mathrm{C}$ in all compositions examined (i.e., $\mathrm{PdCu}$ $1: 1,3: 1$, and $1: 2[7])$. This indicates a much broader stability range of the $\mathrm{B} 2$ phase in nanostructured materials. Upon annealing at higher temperature, the B2-dominant particles evolved differently depending on the original PdCu ratio.

The predominantly $\mathrm{B} 2$ phase nanoparticles formed from PdCu 1:1 mixtures decompose into two alloys of different lattice parameters with different $\mathrm{PdCu}$ ratios when annealed at $750^{\circ} \mathrm{C}$. We denoted these alloys as $\mathrm{Cu}$-rich Alloy-1 (lattice parameter of $3.67 \AA$ ) and Pd-rich Alloy-2 (lattice parameter of $3.81 \AA$ ). This structural evolution cannot be explained by the bulk phase diagram (Figure 2) and has not been reported so far in other $\mathrm{PdCu}$ nanoparticle systems. It indicates the presence of a solubility gap in the nanoscale phase diagram around $\mathrm{Pd}_{50} \mathrm{Cu}_{50}$ above $450^{\circ} \mathrm{C}$. In our case, the phase segregation into a Cu-rich and a Pd-rich phase may be facilitated by the presence of a minority $71 \% \mathrm{Pd}$ phase formed at $450^{\circ} \mathrm{C}$. We note that once the two phases are formed, they continue to grow and do not remix even at high temperature. This is likely due to the separation of the two phases into distinct nanoparticles as suggested in Figure 5.

The observed phase segregation shows the signature of spinodal decomposition. Spinodal decomposition is the process by which a solid solution separates into two different phases throughout the entire volume without nucleation. These two phases typically differ in composition and properties. Spinodal decomposition involves an interaction between composition fluctuations and atomic diffusion. Spinodal decomposition at the nanoscale has been observed in polymers, magnetic and thermoelectric materials, etc. Spinodal decomposition is affected by the finite size of the nanoparticles. Burch and Bazant [17] showed that in certain cases (i.e., intercalated $\mathrm{LiFePO}_{4}$ nanoparticles), the spinodal point and miscibility gap shrink with the decrease in particle size. On the other hand, Palomarez-Baez et al. found that in the case of AuCo, the miscibility gap is preserved even at the lowest sizes due to nanoscale effects of general character [18].

We did not observe any evidence of phase segregation for the $\mathrm{PdCu}$ composition ratio of $1: 2$ [7] or $3: 1$ on $\mathrm{SiO}_{2}$ as discussed in the previous section. The small size of the alloy nanoparticles does, however, limit the growth of the most stable homogeneous phase (i.e., disordered fcc phase) at all compositions [19]. For example, the transformation of the $\mathrm{PdCu}$ 3:1 nanoparticles from the ordered $\mathrm{B} 2$ to the Pd-rich disordered fcc phase was partially suppressed even at high temperature, as evidenced by the remaining B2 phase. Hoffman [20] proposed that phase changes and the stability of a phase are strongly dependent on the atomic misfit between the constituent elements forming the alloy. They found that phase stability is largest where the atomic misfit is large, 


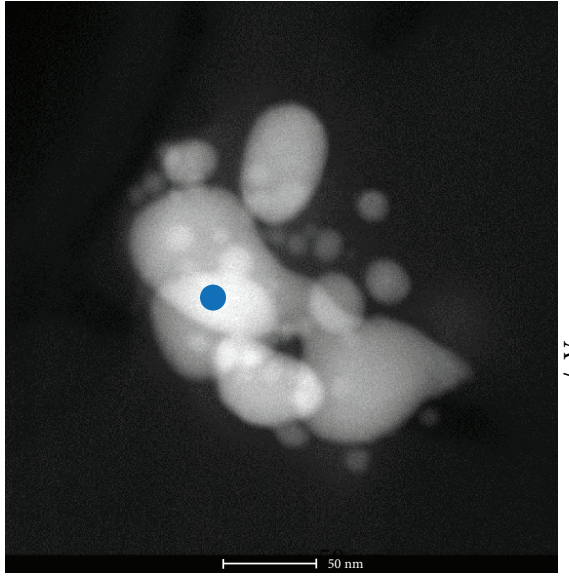

(a)

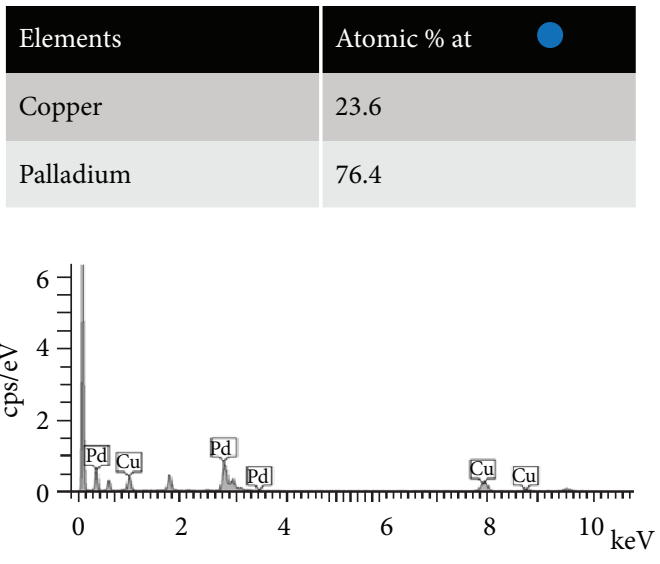

(b)

FIgure 8: (a) HAADF-STEM image of the PdCu $3: 1$ nanoparticle mixture after annealing at $750^{\circ} \mathrm{C}$. Scale bar is $100 \mathrm{~nm}$. (b) EDX spectrum obtained in (a). Table: Pd and Cu compositions from (b).

and the phase transformation temperature shifts to lower temperature. Defects can also affect the route by which a phase develops in nanoalloys. It is possible that the transformation of the B2 phase into the disordered fcc phase is suppressed by defects that pin the grain boundaries. Moreover, Mottet et al. [21] examined the geometrical frustrations induced by chemical ordering in $\mathrm{PdCu}$ nanoparticles and found that they can enhance the stability of certain particles of size-dependent composition.

Phase transformations in nanoparticles are also dependent on the chemical composition of the nanoparticle-supporting substrates. Yang et al. [22] concluded that support nanoalloy interaction tunes the active sites on the nanoalloys for oxygen activation in PtNiCo nanoparticles. They observed phase segregation on silica-supported nanoparticles and random alloy formation for carbon- and titania-supported nanoparticles by oxidative-reduction treatment. Most notably, our preliminary results indicated that the phase segregation seen in the case of $\mathrm{PdCu}$ on $\mathrm{SiO}_{2} / \mathrm{Si}$ was not observed in $\mathrm{PdCu}$ on carbon black and alumina (data not shown here). Detailed studies of PdCu with a composition of $1: 1$ on different substrates such as silica, carbon, alumina, ceria, and titania need to be undertaken to provide clear insights into how the substrate affects the alloy formation and chemical ordering. A combinatorial approach of experiments like high-energy synchrotronbased X-ray diffraction along with atomic pair-distribution function would be beneficial in this case. In situ transmission electron microscopy of these nanoparticles on the same substrates subjected to the same thermochemical conditions as in catalysis can be instrumental in understanding alloy formation and phase transformations at the nanoscales.

\section{Conclusion}

The structural evolution during thermal annealing of $\mathrm{PdCu}$ nanoparticle mixtures with compositions of $1: 1$ and $3: 1$ was investigated using synchrotron-based X-ray diffraction and transmission electron microscopy. In both compositions, the ordered B2 phase is formed during annealing at $450^{\circ} \mathrm{C}$.
However, upon annealing at $750^{\circ} \mathrm{C}$, the two types of mixtures behave dramatically different. In $\mathrm{PdCu} 1: 1$ mixtures, the $\mathrm{B} 2$ phase decomposes into two different alloys, one rich in $\mathrm{Pd}$ and the other poor in Pd. This phase segregation mechanism can be understood as spinodal decomposition involving diffusion. This behavior is attributed to the alloy composition and to finite size effects in nanoparticles. In $3: 1$ composition, the $\mathrm{B} 2$ phase decays incompletely into a disordered Pd-rich fcc alloy during annealing at $750^{\circ} \mathrm{C}$. Our findings are important because the catalytic activity of $\mathrm{PdCu}$ nanoparticles was found by Shan et al. [2] to be related to the composition and degree of ordering in the nanoparticles. In order to create nanoparticles with tunable properties, further structural exploration with other techniques is needed to probe the atomic arrangement of the nanoparticles from the core to the shell with high chemical resolution imaging EDXSTEM. Also of practical interest are the structural evolution of $\mathrm{PdCu}$ nanoparticle mixtures of different sizes and the dependence of the phase diagram on particle size.

\section{Data Availability}

The data used to support the findings of this study are available from the corresponding author upon request.

\section{Conflicts of Interest}

The authors declare that they have no conflicts of interest.

\section{Acknowledgments}

The synchrotron X-ray experiment was performed on beamline X20C at the NSLS, BNL. The use of the NSLS, BNL, was supported by the US Department of Energy Office of Science and Office of Basic Energy Sciences, under Contract no. DE-AC02-98CH10886. The authors are grateful to Jean Jordan-Sweet from IBM for the help with the X-ray experiment. The work is supported in part by NSF (CBET 0709113 and CMMI 1100736). 


\section{References}

[1] J. Yin, S. Shan, M. S. Ng et al., "Catalytic and electrocatalytic oxidation of ethanol over palladium-based nanoalloy catalysts," Langmuir, vol. 29, no. 29, pp. 9249-9258, 2013.

[2] S. Shan, V. Petkov, B. Prasai et al., "Catalytic activity of bimetallic catalysts highly sensitive to the atomic composition and phase structure at the nanoscale," Nanoscale, vol. 7, no. 45, pp. 18936-18948, 2015.

[3] J. Wu, S. Shan, J. Luo, P. Joseph, V. Petkov, and C.-J. Zhong, "PdCu nanoalloy electrocatalysts in oxygen reduction reaction: role of composition and phase state in catalytic synergy," ACS Applied Materials \& Interfaces, vol. 7, no. 46, pp. 2590625913, 2015.

[4] F. Cai, L. Yang, S. Shan et al., "Preparation of PdCu alloy nanocatalysts for nitrate hydrogenation and carbon monoxide oxidation," Catalysts, vol. 6, no. 7, pp. 96-110, 2016.

[5] X. Wang, N. Kariuki, J. T. Vaughey, J. Goodpaster, R. Kumar, and D. J. Myers, "Bimetallic Pd-Cu oxygen reduction electrocatalysts," Journal of the Electrochemical Society, vol. 155, no. 6, pp. B602-B609, 2008.

[6] M. Shao, Q. Chang, J.-P. Dodelet, and R. Chenitz, "Recent advances in electrocatalysts for oxygen reduction reaction," Chemical Reviews, vol. 116, no. 6, pp. 3594-3657, 2016.

[7] V. Mukundan, J. Yin, P. Joseph et al., "Nanoalloying and phase transformations during thermal treatment of physical mixtures of Pd and Cu nanoparticles," Science and Technology of Advanced Materials, vol. 15, no. 2, article 025002, 2014.

[8] D. Mott, J. Yin, M. Engelhard et al., "From ultrafine thiolatecapped copper nanoclusters toward copper sulfide nanodiscs: a thermally activated evolution route," Chemistry of Materials, vol. 22, no. 1, pp. 261-271, 2010.

[9] F. P. Zamborini, S. M. Gross, and R. W. Murray, "Synthesis, characterization, reactivity, and electrochemistry of palladium monolayer protected clusters," Langmuir, vol. 17, no. 2, pp. 481-488, 2001.

[10] Z. Niu and Y. Li, "Removal and utilization of capping agents in nanocatalysis," Chemistry of Materials, vol. 26, no. 1, pp. 72-83, 2013.

[11] M. Li, Pd-Cu Phase Diagram ASM Handbook Volume 3: Alloy Phase Diagrams, P. Villars, H. Okamoto, and K. Cenzual, Eds., ASM International, Materials Park, OH, USA, 2006.

[12] N. N. Kariuki, X. Wang, J. R. Mawdsley et al., "Colloidal synthesis and characterization of carbon-supported $\mathrm{Pd}-\mathrm{Cu}$ nanoparticle oxygen reduction electrocatalysts," Chemistry of Materials, vol. 22, no. 14, pp. 4144-4152, 2010.

[13] M. Yamauchi and T. Tsukuda, "Production of an ordered (B2) CuPd nanoalloy by low-temperature annealing under hydrogen atmosphere," Dalton Transactions, vol. 40, no. 18, pp. 4842-4845, 2011.

[14] D. M. Jones and E. A. Owen, "Experimental study of the variation of the degree of order with temperature in a copperpalladium alloy," Proceedings of the Physical Society Section $B$, vol. 67, no. 4, pp. 297-303, 1954.

[15] K. Baba, U. Miyagawa, K. Watanabe, Y. Sakamoto, and T. B. Flanagan, "Electrical resistivity changes due to interstitial hydrogen in palladium-rich substitutional alloys," Journal of Materials Science, vol. 25, no. 9, pp. 3910-3916, 1990.

[16] Y. Maswadeh, S. Shan, B. Prasai et al., "Charting the relationship between phase type-surface area-interactions between the constituent atoms and oxygen reduction activity of
$\mathrm{Pd}-\mathrm{Cu}$ nanocatalysts inside fuel cells by in operando highenergy X-ray diffraction," Journal of Materials Chemistry A, vol. 5, no. 16, pp. 7355-7365, 2017.

[17] D. Burch and M. Z. Bazant, "Size-dependent spinodal and miscibility gaps for intercalation in nanoparticles," Nano Letters, vol. 9, no. 11, pp. 3795-3800, 2009.

[18] J.-P. Palomares-Baez, E. Panizon, and R. Ferrando, "Nanoscale effects on phase separation," Nano Letters, vol. 17, no. 9, pp. 5394-5401, 2017.

[19] R. Ferrando, J. Jellinek, and R. L. Johnston, "Nanoalloys; from theory to applications of alloy clusters and nanoparticles," Chemical Reviews, vol. 108, no. 3, pp. 845-910, 2008.

[20] D. Hoffman, "Phase stability of alloy catalyst particles," Journal of Catalysis, vol. 27, no. 3, pp. 374-378, 1972.

[21] C. Mottet, G. Tréglia, and B. Legrand, “Theoretical investigation of chemical and morphological ordering in $\mathrm{Pd}_{c} \mathrm{Cu}_{1-c}$ cluster," Physical Review B, vol. 66, no. 4, article 045413, 2002.

[22] L. Yang, S. Shan, R. Loukrakpam et al., "Role of supportnanoalloy interactions in the atomic-scale structural and chemical ordering for tuning catalytic sites," Journal of the American Chemical Society, vol. 134, no. 36, pp. 15048 15060, 2012. 


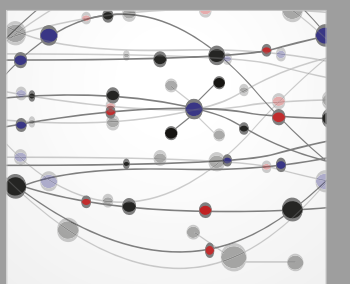

The Scientific World Journal
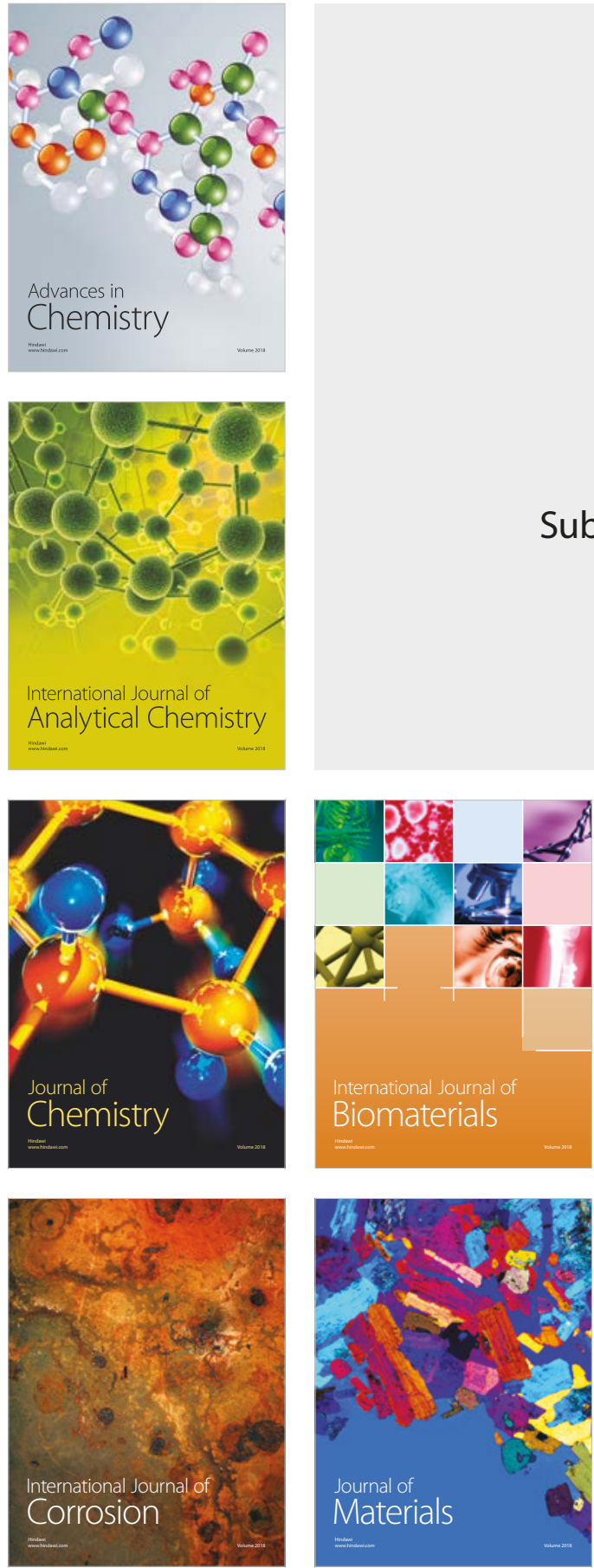

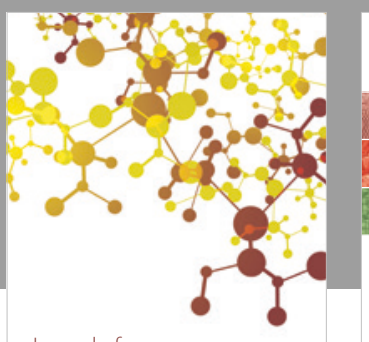

Journal of

Applied Chemistry
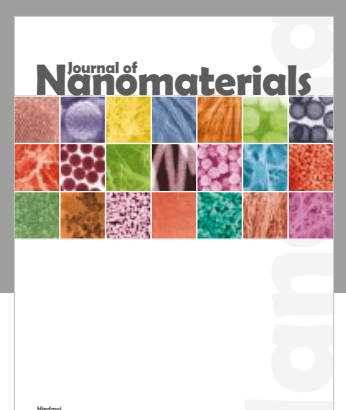

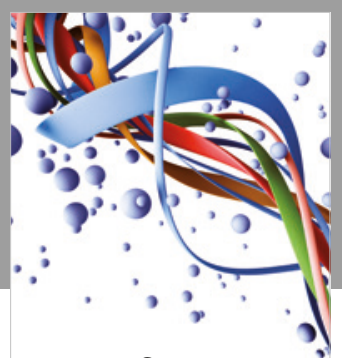

Scientifica

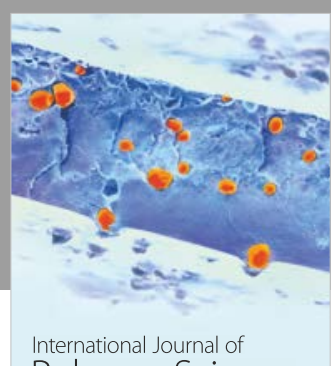

Polymer Science

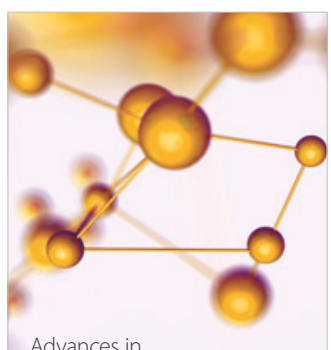

Physical Chemistry
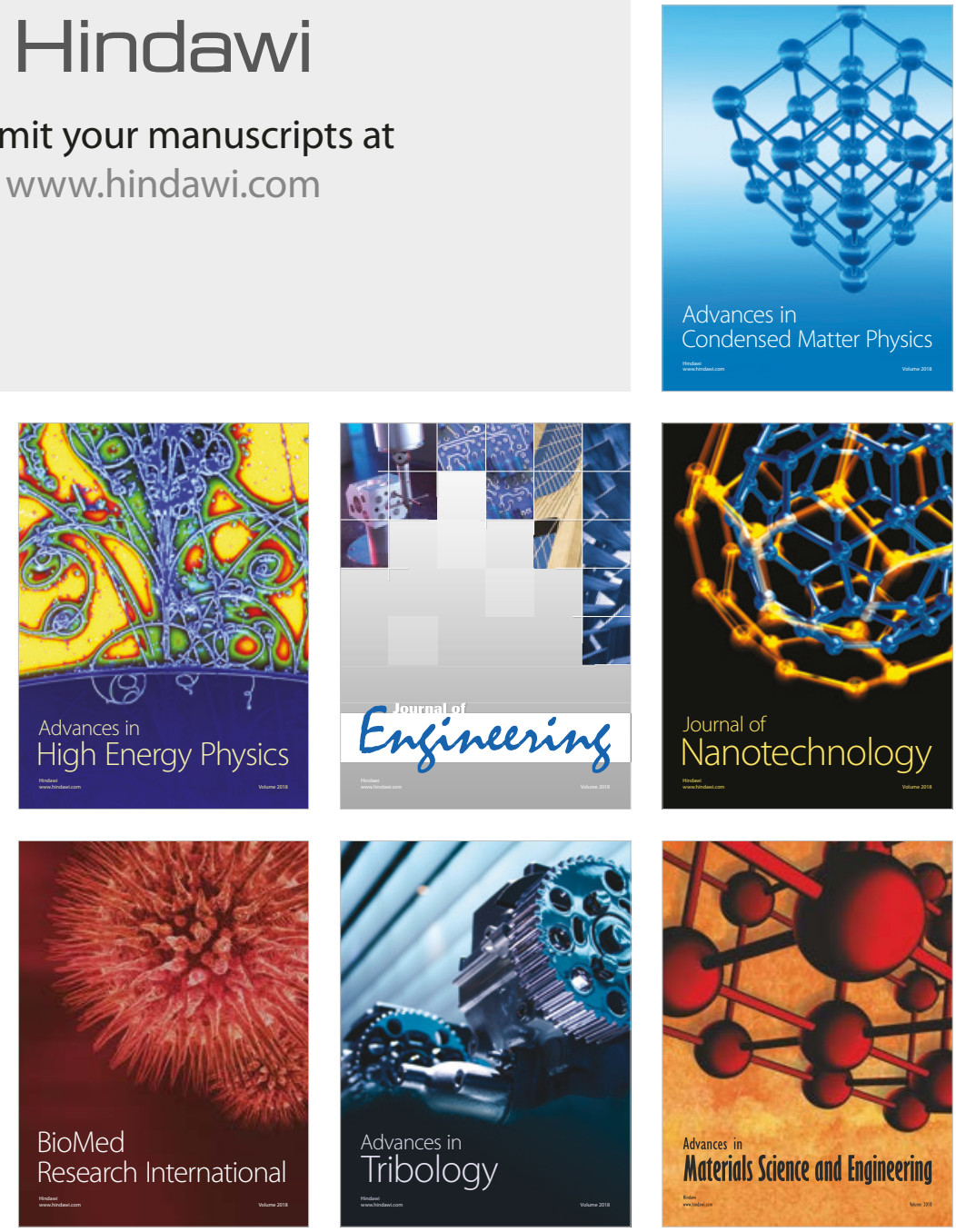